Paper

\title{
Heat-Transfer in Reflector-type Self-Ballasted Compact Fluorescent Lamps
}

\author{
Takeo YASUDA", Masahiro TODA*, Shinichiro MATSUMOTO* and Yuichiro TAKAHARA* \\ "Toshiba Lighting \& Technology Corp.
}

Paper originally published in Japanese in J.IEIJ, Vol.89-No.2, 2005

A part of this paper was presented as follows: by Matsumoto at Tokyo Branch Meeting of IEI-J in 2001, by Takahara at Annual Conference of LEI-J in 2002, by Yasuda at 16th Seminar on Light Source Property and its Application (2002), and by Toda at Tokyo Branch Meeting of IEI-J in 2002.

\begin{abstract}
Self-ballasted compact fluorescent lamps (SBCFL) are widely used to replace incandescent lamps (IL) to save energy. We studied the heat-transfer phenomena of SBCFLs with outer envelopes by measuring the temperatures of the lamp parts, the power consumption, and the luminous output, and by calculating the energy balance. The methods applied were heat-transfer network analysis and computational fluid dynamics (CFD) using FLUENT ${ }^{\circledR}$ software. The heat loss increased in reflector-type SBCFLs as compared to SBCFLs with non-reflective outer envelopes, and was estimated at about $3 \mathrm{~W}$ when the total lamp power was $22 \mathrm{~W}$. This results in a temperature rise of $20 \mathrm{~K}$ in the plastic holder, and a maximum rise of $10 \mathrm{~K}$ at the electronic components on the circuit board. Accordingly, we have developed a $12 \mathrm{~W}$ reflector-type SBCFL, which replaces a $60 \mathrm{~W}$ incandescent, not a $22 \mathrm{~W}$ SBCFL replacing a $100 \mathrm{~W}$ incandescent $\mathrm{R}$-lamp, due to the importance of thermal reliability.
\end{abstract}

\section{KEYWORDS: heat-transfer, self-ballasted, compact fluorescent lamp, network analysis, computational fluid} dynamics

\section{Introduction}

In the recent years, the demand for the self-ballasted compact fluorescent lamps (SBCFL), which have high energy saving effects, has been increasing due to increased concerns for environmental issues. Although almost all self-ballasted compact fluorescent lamps currently being sold in the market contain an electronic circuit, their thermal loading has been increasing due to efforts to reduce their size and increase output ${ }^{12)}$ in order to make their sizes closer to those of incandescent lamps. Some of these lamps have an outer envelope of the A-type, G-type, or T-type ${ }^{3)}$ covering the outside of the curved discharge tube for the sake of the appearance of the merchandise, and this structure is one of factors that has caused an increase in the tem. perature of the electronic circuit. Therefore, it is important to reduce the temperature of the electronic circuit and the surrounding parts in order to improve properties and reliability related to temperature in selfballasted compact fluorescent lamps, and it is necessary to clearly understand the heat transfer phenom. ena as a preliminary step.

However, there have been few papers presented on the electrical circuit temperature of the compact fluo- rescent lamps in the past, and we can list only two: a report on the thermal network analysis of compact fluorescent lamps without outer envelopest), and a report on measuring the results of dimensional design versus electronic parts ${ }^{5}$. Hence, we have implemented a thermal network analysis ${ }^{6}$, which is the same method as was applied in reference (4) on compact fluorescent lamps with envelopes, and also implemented a heat transfer analysis8) with FLUENT ${ }^{\circledR}$ thermo-fluid analysis software in the development of compact fluorescent lamps with reflector-type envelopes ${ }^{7)}$, and we are going to report these results.

2. Thermal network analysis of $22 \mathrm{~W}$ lamp with envelope

2.1 Specification of the SBCFL on which the experiments and analysis were implemented

The lamp that was evaluated in this chapter was a replacement for the $100 \mathrm{~W}$ incandescent lamp. Its model name was EFA22EL and had a power consumption of $22 \mathrm{~W}$, tri-chromatic warm white color, with a total luminous flux of about $1500 \mathrm{~lm}^{2}$. Fig. 1 shows its structure. A hot cathode fluorescent tube, made up of four U-type tubes of $11 \mathrm{~mm}$ diameter, is combined with 
an electronic circuit that operates the light with a sinusoidal current of about $60 \mathrm{kHz}$, and can be directly adapted to an E26 socket. The symbol h and the inserted phrases of "reflective film," "control line," and "light aperture" are modifications made for the experiment of the reflector-type SBCFL in Chapter 3. In this Chapter 2, experiment and analysis was made on regular product in which a milky white diffusion coating is used so that light transmission be around $95 \%{ }^{9}$ ).

2.2 Heat transfer model and thermal network analysis

The method of thermal network analysis was set as

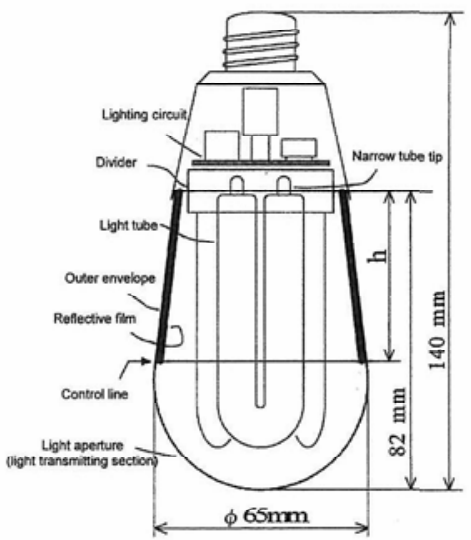

Figure 1 Structure of EFA22EL the same as was used in references (4) and (10), and we have referred to reference (11) for setting the coefficient of thermal conductivity for natural convection, and so on. Fig. 2 shows the heat-transfer network model corre-

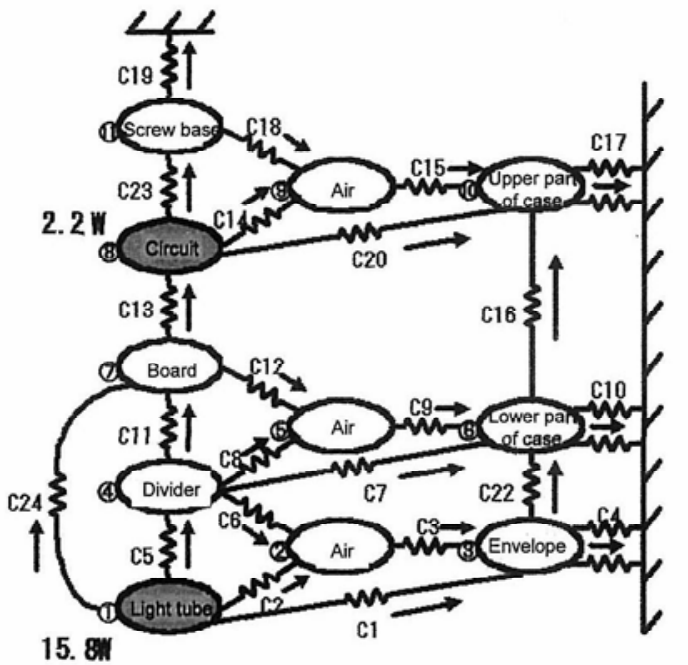

Figure 2 Heat-transfer network model

Table 1 Representative area mentioned by each node

\begin{tabular}{|c|l|c|l|}
\hline (1) & Light tube & (7) & Circuit board \\
\hline (2) & Air in outer envelope & (8) & Circuit \\
\hline (3) & Outer envelope & (9) & Air in case \\
\hline (4) & Divider & (ii) & Upper part of case \\
\hline (5) & Air in between divider and circuit board & III & Screw base \\
\hline (6) & Lower part of case & \multicolumn{2}{|l}{} \\
\cline { 1 - 2 }
\end{tabular}

Table 2 Heat-transfer network equations between nodes

\begin{tabular}{|l|l|}
\hline (1) $Q 1+Q 2+Q 5+Q 24=15.8-Q 25$ \\
\hline (2) $-Q 2+Q 3-Q 6=0$ \\
\hline (3) $-Q 1-Q 3+Q 4+Q 22=0$ \\
\hline$(4)$ & $-Q 5+Q 6+Q 7+Q 8+Q 11=0$ \\
\hline (5) $-Q 8+Q 9-Q 12=0$ \\
\hline (6) $-Q 7-Q 9+Q 10+Q 16-Q 22=0$ \\
\hline (7) $-Q 11+Q 12+Q 13-Q 24=0$ \\
\hline (8) $-Q 13+Q 14+Q 20+Q 23=2.2$ \\
\hline (9) $-Q 14+Q 15-Q 18=0$ \\
\hline (11) $-Q 15-Q 16+Q 17-Q 20=0$ \\
\hline (11) $Q 18+Q 19-Q 23=0$ & $Q 13=C 13 \times(T 7-T 8)$ \\
\hline$Q 1=C 1 \times(T 1-T 3)$ & $Q 14=C 14 \times(T 8-T 9)$ \\
\hline$Q 2=C 2 \times(T 1-T 2)$ & $Q 15=C 15 \times(T 9-T 10)$ \\
\hline$Q 3=C 3 \times(T 2-T 3)$ & $Q 16=C 16 \times(T 6-T 10)$ \\
\hline$Q 4=C 4 \times(T 3-T 6)$ & $Q 17=C 17 \times(T 10-T \circ)$ \\
\hline$Q 5=C 5 \times(T 1-T 4)$ & $Q 18=C 18 \times(T 11-T 9)$ \\
\hline$Q 6=C 6 \times(T 4-T 2)$ & $Q 19=C 19 \times(T 11-T \infty)$ \\
\hline$Q 7=C 7 \times(T 4-T 6)$ & $Q 20=C 20 \times(T 8-T 10)$ \\
\hline$Q 8=C 8 \times(T 4-T 5)$ & $Q 21=C 21 \times(T 8-T 6)$ \\
\hline$Q 9=C 9 \times(T 5-T 6)$ & $Q 22=C 22 \times(T 3-T 6)$ \\
\hline$Q 10=C 10 \times(T 6-T 6)$ & $Q 23=C 23 \times(T 8-T 11)$ \\
\hline$Q 11=C 11 \times(T 4-T 7)$ & \\
\hline$Q 12=C 12 \times(T 7-T 5)$ & \\
\hline
\end{tabular}


sponding to this experiment. Table 1 shows the representative areas mentioned by each node and Table 2 shows the simultaneous equations used to express the relationship between the temperature at each node, the heat conductance (the reciprocal of the heat transfer resistance), and the thermal flow. Here, $Q$ is the heat flow rate (W), $C$ is the heat conductance (W/K), and $T$ is the absolute temperature (K). Regarding the heat transfer vehicles, $C 5,7,13,16,19$, and 22 express heat conduction, $\mathrm{C} 2,3,6,8,9,12,14,15$, and 18 express convection, $C 1,11,20,21,23$, and 24 express radiation, and $C 4,10$, and 17 express the sum of the convection and radiation. However, C21, which shows a route of radiation connecting the case bottom (6) and the circuit (8), is not included in Fig. 2 since it was regarded as being unnecessary during evaluation and was disregarded. Although $T \infty$ means an infinite ambient temperature, it is $25^{\circ} \mathrm{C}(298 \mathrm{~K})$ here. By the way, each value of $C$ was obtained by approximation based upon the geometric dimensions and the succeeding multiplication by adjusting coefficients to reflect the experimental results of temperature measurement.

The exothermic bodies here are the light tube (1) and the circuit (8), and each value was obtained as follows. Regarding the heat release value of the circuit, it was known from an experiment with the conditions of an ambient temperature $25^{\circ} \mathrm{C}$, the lamp operated with the bare screw base upward, and a rated input of $100 \mathrm{~V}$ at $50 \mathrm{~Hz}$, that the electric power consumption of the whole lamp was around $22.4 \mathrm{~W}$, the electric power input to the light tube at around $90 \%$ circuit efficiency was around $20.2 \mathrm{~W}$, and electric power consumption of the ballast was around $2.2 \mathrm{~W}$. Then, in regard to the electric power consumption of the light tube, the visible light of trichromatic warm white color, and a total luminous flux of $1500 \mathrm{~lm}$ equivalent to around $4.4 \mathrm{~W}$ is regarded to have escaped from the thermal network system being studied, and the remaining $15.8 \mathrm{~W}$ was put as the heat release in the initial calculation. Although there is a heat flow rate $Q 25$ to be deducted from 15.8 in item (1) in Table 2, this represents a part of heat radiated from light tube that is transmitted through the outer envelope to escape the thermal network system, as was the case with the visible light. This ratio of heat radiation transmitted through the outer envelope $T M(\%)$ was obtained by the following Equation (1):

$$
T M=\frac{\varepsilon \int_{0}^{\infty} I(\lambda) M_{e, \lambda}(T) d \lambda}{\varepsilon M_{e}(T)}
$$

Here, $\varepsilon$ is the emissivity of glass, $M_{e}(T)$ is the radiant emittance $\left(\mathrm{W} / \mathrm{m}^{2}\right), \lambda$ is the wavelength $(\mu \mathrm{m}), M_{e, \lambda}(T)$ is

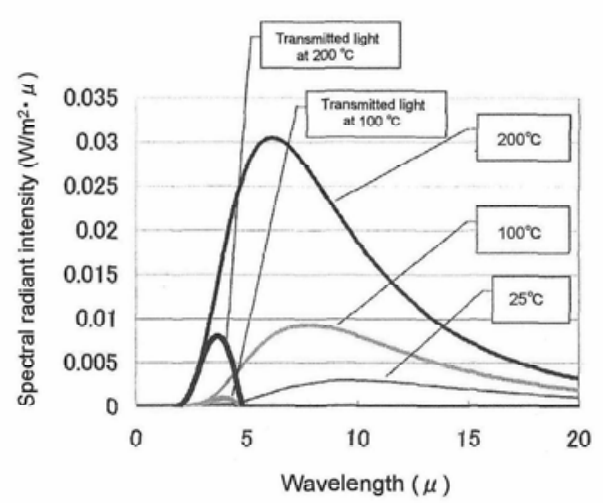

Figure 3 Relation between the temperature of light tube and transmitted radiation

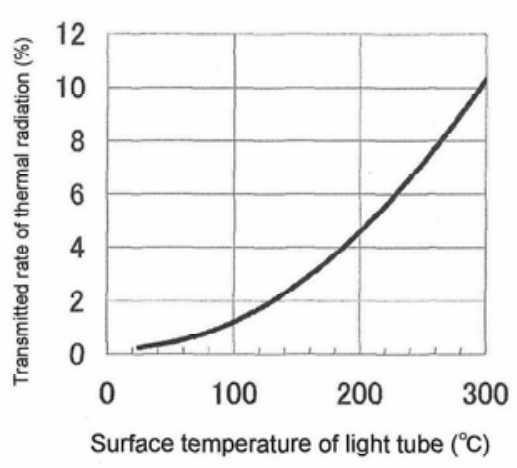

Figure 4 Relation between the temperature of light tube and the transmitted rate

the spectral radiant emittance $\left(\mathrm{W} /\left(\mathrm{m}^{2} \cdot \mu \mathrm{m}\right)\right), T$ is the absolute temperature $(\mathrm{K})$, and $I(\lambda)$ is the spectral transmittance of the outer envelope. Although there is no data on $I(\lambda)$ for a milky white diffusion envelope, we have assumed that below $2.9 \mu \mathrm{m}$ is $95 \%$, above $4.8 \mu \mathrm{m}$ is $0 \%$, and the transmittance is reduced linearly in the range from $2.9 \mu \mathrm{m}$ to $4.8 \mu \mathrm{m}$, using the data for the spectral transmittance for soda lime glass as a reference. Fig. 3 shows the calculated results of the spectral distribution of the thermal radiation at light tube temperatures of $25^{\circ} \mathrm{C}, 100^{\circ} \mathrm{C}$, and $200^{\circ} \mathrm{C}$, as well as the spectral distribution of the thermal radiation transmitting through the outer envelope. Fig. 4 shows the relationship between the surface temperature of the light tube and the rate of thermal radiation transmission. The temperature of an SBCFL is roughly in the range from $100^{\circ} \mathrm{C}$ to $200^{\circ} \mathrm{C}$, although it varies by brand, and the transmitted thermal radiation is only in the range from $1 \%$ to $5 \%$, so there is no significant error, even if it is assumed that the outer envelope is opaque to thermal radiation.

\subsection{Analysis of results}

Table 3 compares the calculated and measured values of the temperature and electric power for major parts of the lamp, and the differences in temperatures for each 
Table 3 Comparison between calculation results and measured data

\begin{tabular}{|r|c|c|}
\hline Position of parts & Measured value & Calculated value \\
\hline Globe $\left({ }^{\circ} \mathrm{C}\right)$ & 89 & 89 \\
\hline Divider $\left({ }^{\circ} \mathrm{C}\right)$ & 152 & 152 \\
\hline Upper part of case $\left({ }^{\circ} \mathrm{C}\right)$ & 76 & 72 \\
\hline Lower part of case $\left({ }^{\circ} \mathrm{C}\right)$ & 82 & 76 \\
\hline Average of circuit $\left({ }^{\circ} \mathrm{C}\right)$ & 119 & 123 \\
\hline Screw base $\left({ }^{\circ} \mathrm{C}\right)$ & 62 & 63 \\
\hline Electric power at light tube $(\mathrm{W})$ & 20.2 & 20.2 \\
\hline Consumption power at circuit (W) & 2.2 & 2.2 \\
\hline
\end{tabular}

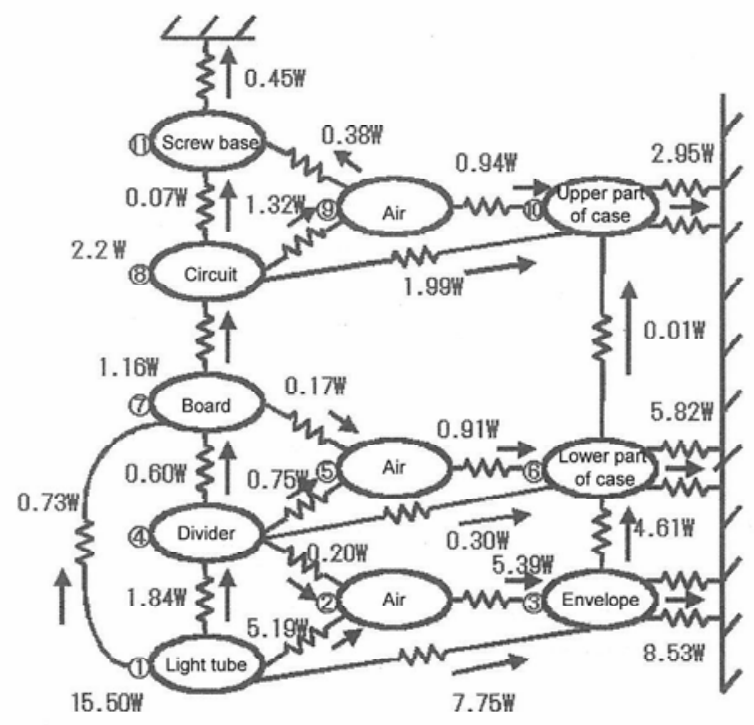

Figure 5 Calculated result on the heat-transfer of EFA22EL

part is within $10^{\circ} \mathrm{C}$. Temperature measurements were made using a copper-constantan thermocouple with a $0.2 \mathrm{~mm}$ wire diameter $\varphi$. By the way, it is not surprising that the calculated temperature value matched the measured values well because adjusting coefficients were applied, and, instead, the more valuable result obtained by the calculations was the status of the thermal flow, as shown in Fig. 5. The temperature of the light tube reached approximately $180^{\circ} \mathrm{C}$ and the thermal radiation transmitted through the outer envelope as obtained per the description in paragraph 2.2 was $0.3 \mathrm{~W}$, which is equivalent to around $4 \%$.

Among the heat out of the light tube, the heat flow rate to the circuit via the board was $1.16 \mathrm{~W}$, which was an unexpectedly low level. However, the surface area of the case surrounding the circuit is small compared to the outer envelope that covers the light tube, and the channels to allow the escape of the generated heat are fundamentally limited, so the temperature of the circuit is considered to be easily increased even by small heat generation.

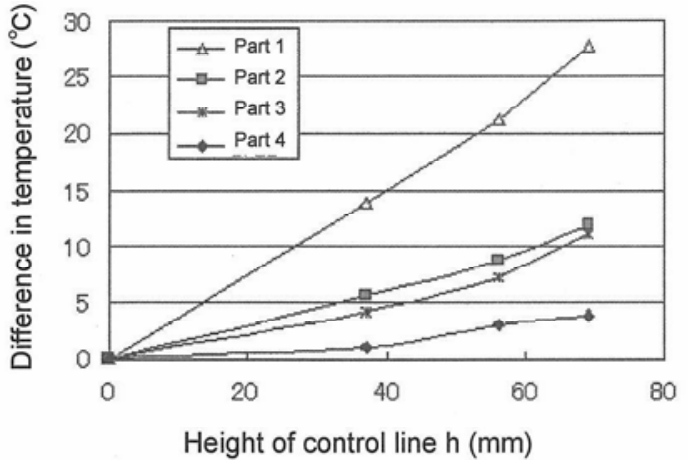

Figure 6 Relation between the temperature of lamp part and the height of control line

3. Heat analysis of SBCFL with a reflector envelope 3.1 Temperature measurement of a $22 \mathrm{~W}$ lamp with envelope

As suggested by the reflector-type incandescent lamps already on the market, there is a market need for SBCFLs with high directional luminance for downlight applications even with a somewhat reduced total luminous flux. Hence, a lamp with a structure as shown in Fig. 1 was produced experimentally for the purpose of basic testing and its properties were evaluated. The symbol $h$ in the figure indicates the height of the control line for the aluminum reflective film formed on the inside surface of the envelope by means of vacuum vapor deposition. Fig. 6 shows the temperature increase of parts of the lamp with varied values of $h$ against the temperature of the parts in the regular product. Here, the regular product is a lamp without a reflective film but with a milky white diffusive film formed in its inside. Parts 1, 2, 3, and 4 correspond to the partition plate, the narrow tube tip, parts on the lower surface of the circuit board, and parts on the upper surface of the circuit board, respectively. It is known from Fig. 6 that the temperature of each part increased in parallel with an increase in the control level and that especially the temperature of the divider, which is close to the light tube, increased remarkably. In view of the results in the previous Chapter 2, it is assessed that, a portion of around $7.8 \mathrm{~W}$ of the heat radiated from the light tube to 
Table 4 Specifications of the developed reflector-type SBCFL Each lamp color is tri-chromatic warm white (2800K)

\begin{tabular}{|r|c|c|}
\hline & $\begin{array}{c}\text { SBCFL with reflector } \\
\text { type envelope } \\
\text { (newly developed) }\end{array}$ & $\begin{array}{c}\text { SBCFL with milky white } \\
\text { diffusion film.A type } \\
\text { (existing line) }\end{array}$ \\
\hline Rated input power (V) & 100 & 100 \\
\hline Rated consumption power (W) & 12 & 12 \\
\hline Total light flux (lm) & 560 & 810 \\
\hline Central luminance (cd) & 115 & 72 \\
\hline Maximum luminance (cd) & 135 & 79 \\
\hline
\end{tabular}

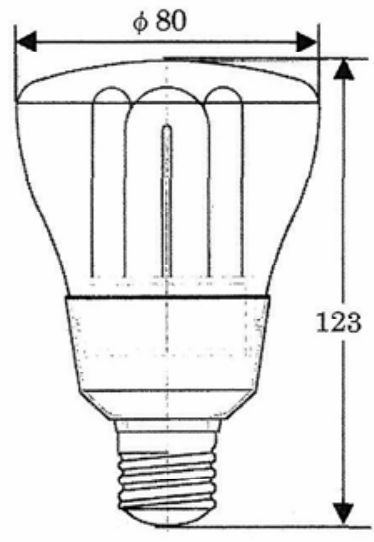

Figure 7 Dimensions of the developed lamp with reflector-type envelope

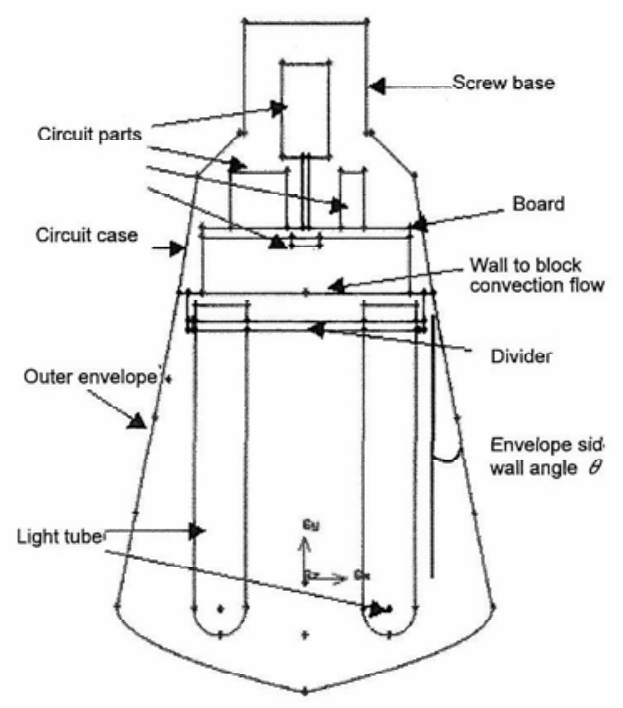

Figure 8 2D-Model of the lamp

the outer envelope was reflected by the aluminum film and also a portion of the visible light equivalent to $4.4 \mathrm{~W}$ was reflected by the same, they were not used effectively and, as a result, were transferred in the form of heat throughout the inside of the system. For example, the total luminous flux with a control line height of 56 $\mathrm{mm}$ was around $75 \%$ of the flux in the regular product

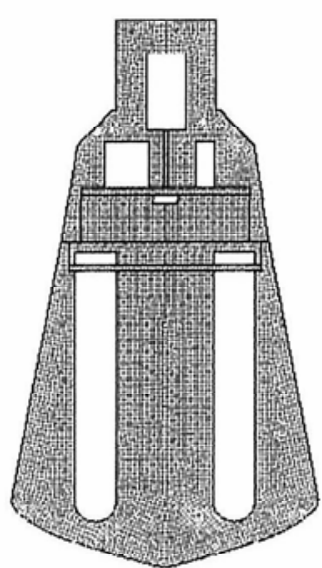

Figure 9 Meshes of 2D-model

when comparative photometry was done using and integrating sphere of $\varphi 3 \mathrm{~mm}$, and it is considered that approximately $3 \mathrm{~W}$, or around $25 \%$ of the $12.2 \mathrm{~W}$ total radiated heat and visible light, became heat and caused the temperature increase in the parts.

An increase in temperature of the circuit parts shortens the life of the lamp, and also it is undesirable because a more expensive resin with higher heat resistance has to be used for the partition plate, a part made of resin, in parallel with an increase in the operating temperature.

\subsection{Example of two-dimensional thermal flow analysis using FLUENT ${ }^{3}$}

Table 4 and Fig. 7 show the final specification of the developed product, which was designed to achieve 560 $\mathrm{lm}$ total luminous flux, which is equivalent to $60 \mathrm{~W}$ reflector-type incandescent lamp, and as a result realized a $12 \mathrm{~W}$ power consumption. Compared to an A-shaped SBCFL of $12 \mathrm{~W}$ with $810 \mathrm{~lm}^{12}$, the center beam candlepower is about 1.6 times higher. A thermal flow analysis of a two-dimensional model of this reflector-type lamp was implemented.

Fig. 8 and Fig. 9 show diagrams of the model and the mesh formation. Although there is no wall to block convection, as shown in Fig. 8, in the actual product, it was set in the model in order to check its effect on tempera 
Table 5 Conditions of calculation

\begin{tabular}{|l|c|c|c|c|}
\hline & $\begin{array}{c}\text { Reflective film } \\
\text { on envelope }\end{array}$ & $\begin{array}{c}\text { Envelope side } \\
\text { wall angle } \theta\end{array}$ & $\begin{array}{c}\text { Wall to block } \\
\text { convection }\end{array}$ & $\begin{array}{c}\text { Heat release } \\
\text { value }\end{array}$ \\
\hline Condition (1) & No & $10 \mathrm{deg}$. & Without wall & $\begin{array}{c}\text { Equivalent to } \\
\text { product of } 22 \mathrm{~W}\end{array}$ \\
\hline Condition (2) & Yes & $10 \mathrm{deg}$. & Without wall & $\begin{array}{c}\text { Equivalent to } \\
\text { product of } 22 \mathrm{~W}\end{array}$ \\
\hline Condition (3) & Yes & $20 \mathrm{deg}$. & Without wall & $\begin{array}{c}\text { Equivalent to } \\
\text { product of } 22 \mathrm{~W}\end{array}$ \\
\hline Condition (4) & Yes & $10 \mathrm{deg}$. & With wall & $\begin{array}{c}\text { Equivalent to } \\
\text { product of } 22 \mathrm{~W}\end{array}$ \\
\hline Condition (5) & Yes & $10 \mathrm{deg}$. & Without wall & $\begin{array}{c}\text { Equivalent to } \\
\text { product of } 12 \mathrm{~W}\end{array}$ \\
\hline
\end{tabular}

Table 6 Calculated temperatures at each position $\left({ }^{\circ} \mathrm{C}\right)$

\begin{tabular}{|l|c|c|c|}
\hline & Center of divider & Circuit part a & Circuit part b \\
\hline Condition (1) & 164 & 137.5 & 69 \\
\hline Condition (2) & 172 & 167.5 & 77.5 \\
\hline Condition (3) & 167.5 & 152.5 & 73 \\
\hline Condition (4) & 177.5 & 137 & 70 \\
\hline Condition (5) & 138 & 120 & 62 \\
\hline
\end{tabular}

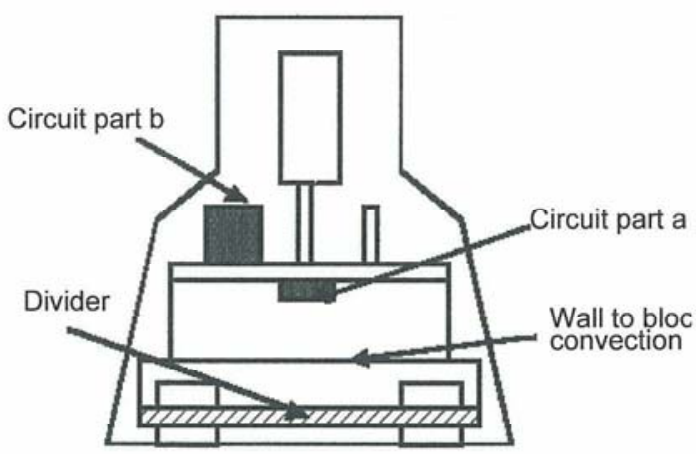

Figure 10 Positions of the lamp temperature indicated

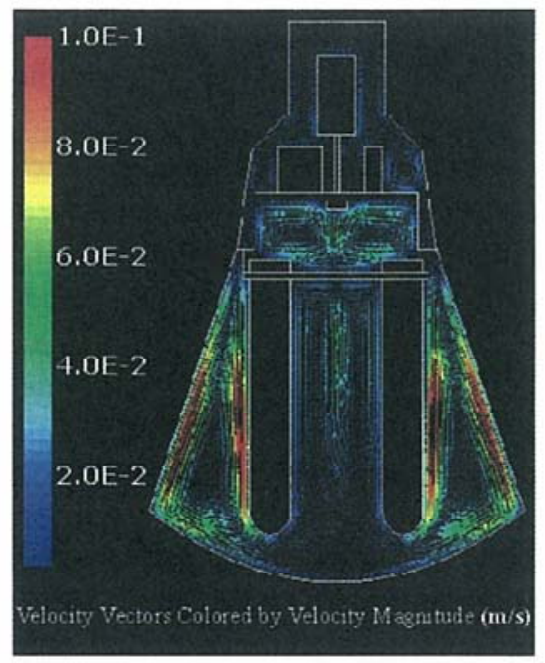

Figure 11 Result on the calculated convection under the condition

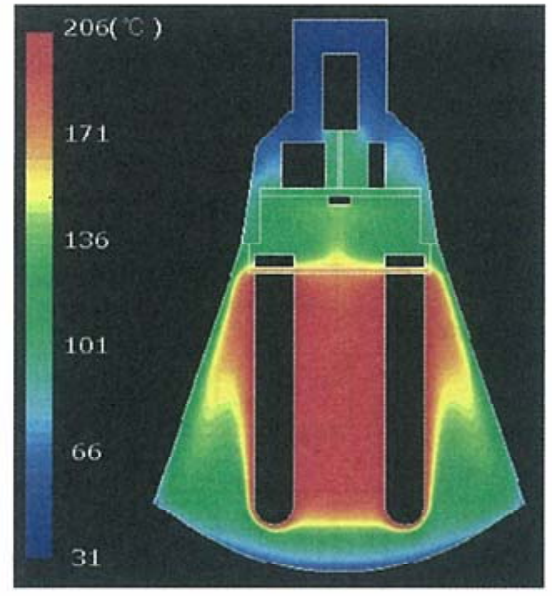

Figure 12 Results on the calculated temperature distribution under the condition

ture reduction. Table 5 shows the conditions set for the calculation. In this section, the circuit parts were not regarded as exothermic bodies, and it was assumed that only the surface of the light tube generates heat in order to calculate its influence on the temperature of the circuit parts. The density of heat generation was put as $900 \mathrm{~W} / \mathrm{m}^{2}$ for a product equivalent to a lamp input power of $22 \mathrm{~W}$ and as $450 \mathrm{~W} / \mathrm{m}^{2}$, or half of the former, for $12 \mathrm{~W}$ equivalence. An emissivity of 0.04 was assumed for the aluminum reflective film of the outer envelope, and an emissivity of 0.89 was assumed for the soda lime glass in the case of no reflective film ${ }^{13}$. Thicknesses of screw base, case, outer envelope, and wall for blocking 
were assumed as $0.5 \mathrm{~mm}, 1 \mathrm{~mm}, 1 \mathrm{~mm}$, and $1 \mathrm{~mm}$, respectively. Circuit parts were assumed to be of thermal insulating material, and the overall heat transfer coefficient by natural convection from the screw base, case, and envelope to the outside was set at $5 \mathrm{~W} /\left(\mathrm{m}^{2} \cdot \mathrm{K}\right)$.

The calculation results are shown in Table 6, in which the temperature is shown at three positions or, as shown in Fig. 10, the center of the divider, the circuit part a on the lower surface of the board, and the circuit part $b$ on the upper surface of the board. By the way, measurement increment is $0.5^{\circ} \mathrm{C}$. The following was clarified: (a) through comparison of Conditions (1) and (2), it was found that an increase in temperature of the parts is caused by the formation of the reflective film on the outer envelope; (b) although we obtained a result that heat reduction effect in the case of Condition (5), a reduced heat release value, was apparently large, we noted that, when Conditions (2) and (3) were compared, there was another heat reduction effect in the case of an enlarged envelope side wall angle and a resulting enlarged surface area, (c) in view of the data for Condition (4), when convection between the divider and the board is blocked, the temperature of the circuit parts is reduced but the temperature of the divider is increased, and, although there is a blocking effect, the total effect seems to depend upon the design. Fig. 11 and Fig. 12 show examples of calculations under condition (3). The results show that convection is developed in a space between the light tube and the outer envelope as well as in a space between the divider and the board, as described above.

\subsection{Example of three-dimensional thermal flow analy- sis using FLUENT ${ }^{3}$}

Although it is possible to investigate the qualitative changes in lamp temperature by the two-dimensional model per the previous Section 3.2, there were the flaws that the heat release of the circuit was neglected and that the inside space of a U-type light tube is assumed as homogeneous because it is closed except bottom surface. Hence, we developed a three-dimensional model of a $22 \mathrm{~W}$ reflector-type SBCFL and added the heat release values of each part of the electronic circuit as obtained by experiments in the setup conditions. Fig. 13 shows the shape of the model. Circuit parts a, b, c, d, and e are an electric-field-effect transistor (MOS-FET, regarded two pieces as one package), a wire-wound ballast, an aluminum electrolytic capacitor for ripple filtering, a rectifier (REC), and a resonant capacitor respectively, and parts a and $\mathrm{d}$ are surface-mount parts on the back of the board. Their heat release values are $0.18 \mathrm{~W}, 0.41$ $\mathrm{W}, 0.14 \mathrm{~W}, 0.32 \mathrm{~W}$, and $0.44 \mathrm{~W}$ respectively, which were obtained by electrical or thermal measuring. These five values add up to around $1.5 \mathrm{~W}$, which can represent

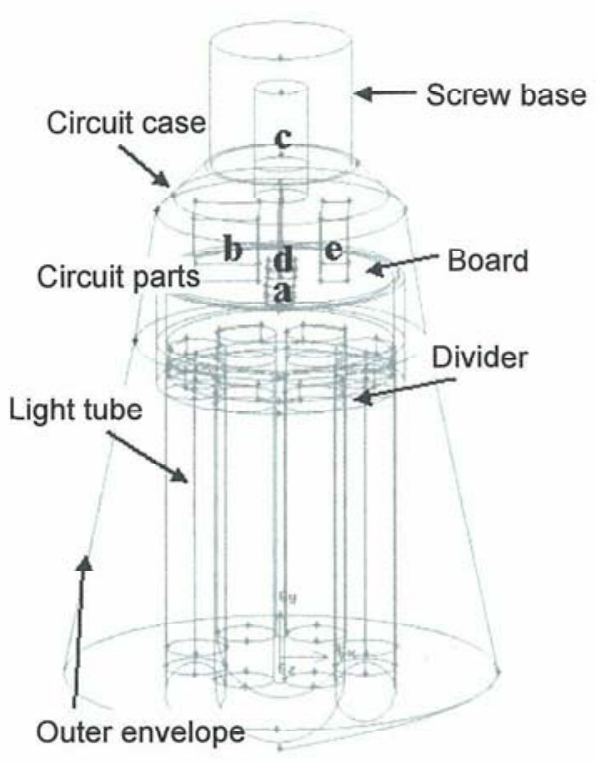

Figure 13 3D-analysis model

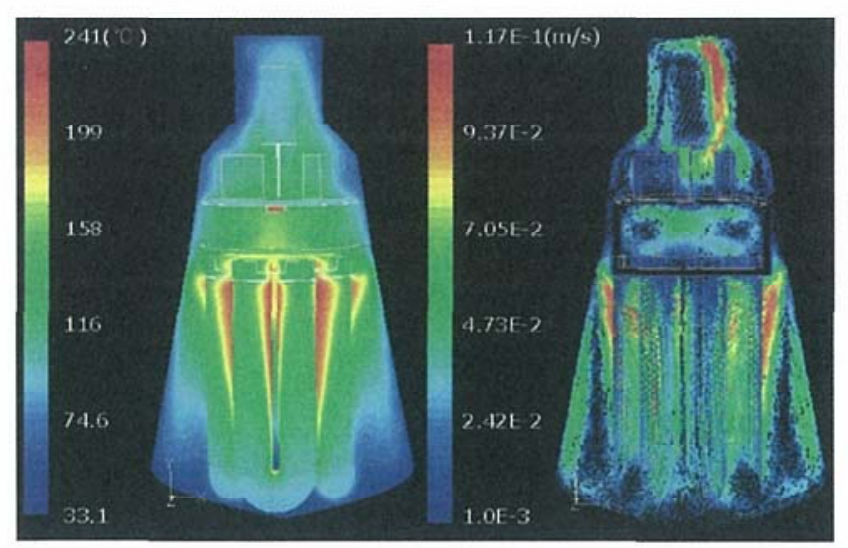

Figure 14 Result of 3D-analysis for example

around $70 \%$ of the $2.2 \mathrm{~W}$ of the circuit loss. Six parts of five categories built into this model are the main heat releasing parts in the half-bridge circuit ${ }^{14}$. If all the parts are taken into consideration, the modeling will be complicated and the calculation time will be enormous. Also, if the whole circuit loss of $2.2 \mathrm{~W}$ is allocated to parts a through e, the heat release values per surface area of each part is assumed to increase resulting in a local elevation of temperature. Therefore, the circuit loss was put as around $1.5 \mathrm{~W}$ for the main parts alone for this study. Regarding the electric power to be consumed as the heat of the light tube, it is necessary to add around $3 \mathrm{~W}$ due to a reason as explained in paragraph 3.1 on top of the $15.5 \mathrm{~W}$ as shown in Fig. 5, and thus it was put as $18 \mathrm{~W}$ in this study. The heat transfer coefficient due to natural convection was set at $5 \mathrm{~W} /\left(\mathrm{m}^{2}\right.$. $\mathrm{K})$, similar to the previous section, and it was assumed that a reflective film was formed on the inside surface of 
the conic portion of the outer envelope.

The temperature distribution is shown in the left side of Fig. 14, and the status of the convection is shown in the right side. In the three-dimensional model, as compared to the two-dimensional model, it was shown that convection is developed in the interstices of the light tubes and that there are thermal gradients in the top and bottom and the inside and outside in the envelope and heat transfer by natural convection is actively made. On the other hand, regarding the electronic circuit section above the board, although there is an updraft of high temperature air between part $c$ and part e, it was shown that, in general, the temperature is reduced flatly toward the upper side and a comparatively low temperature portion is formed in the vicinity of the inside of the screw base. However, there was a trend noted that the absolute values of the calculated temperatures are higher than the measured levels in the high temperature section and they are lower than the measured levels in low temperature section. In order to increase the precision of the calculation in the future, it is necessary to re-examine the boundary conditions, since, although the calculation with this model assumed a constant heat transfer coefficient irrespective of location, the heat transfer coefficient is assessed to be lower toward the upper side of the lamp taking into consideration the fact that the air outside the lamp causes natural convection.

\section{Summary}

In regard to the SBCFL with an outer envelope, the status of the heat transfer was studied applying two methods, heat-transfer network analysis and analysis using FLUENT ${ }^{\circledR}$ thermo-fluid software. As a result of the heat-transfer network analysis, we have obtained the calculation result that the heat flow rate from the light tube to the circuit in $22 \mathrm{~W}$ lamp is around $1.2 \mathrm{~W}$, which was unexpectedly small. However, it was found that designing a reflector-type SBCFL with a power consumption of $22 \mathrm{~W}$ will increase the thermal loading for the lighting circuit parts and the divider made of resin, since the sum of the heat of the visible light and the heat radiated from the surface of the light tube is estimated at around $12.2 \mathrm{~W}$ and around $3 \mathrm{~W}$, or around $25 \%$ of the $12.2 \mathrm{~W}$ is assessed to be the source of heat generation in the lamp system. Based upon the analysis results with the two-dimensional model using FLUENT ${ }^{\top}$, it was clarified that (1) convection developed between the outer envelope and the light tube as well as between the divider and the circuit board, and (2) enlargement of the surface area of the outer envelope by enlargement of its opening angle or reduction in the consumed power of the lamp itself contribute to a temperature reduction in the parts. Also, in the calculation with the three-dimensional model, it was shown that convection is developed in the interstices of the light tubes and that a low temperature space is formed in the vicinity of the inside of the screw base. These analysis results were applied for our development of an SBCFL with reflector-type envelope with a rated power of $12 \mathrm{~W}$. Topics for future study are to confirm the heat flow rate as assessed in this study by actual measuring using heat flux sensors and so on and to reexamine the setting of the boundary conditions for thermo-fluid analysis.

\section{References}

(1) T. Yasuda, K. Nishio, Y. Shibahara and S. Hakuta: The Self-Ballasted Compact Fluorescent Lamp of an A60 Bulb Shape, J. Light \& Vis. Env., 24-2, pp.1$7(2000)$.

(2) Shibahara, Nishio and Shirota: Study on Down Sizing of Self-ballasted Compact Fluorescent Lamp for High Lumen Output, Proc. 2000 Annual Conf. IEI Jpn., No.9 (2000)(in Japanese).

(3) Edition by IEI-J: Lighting Handbook 2nd Edition, OHM Sha, p.110(2003)(in Japanese).

(4) Honda, Yuge, Itoh, Ishizuka and Sasaki: Thermal Simulation of Compact Self-ballasted Fluorescent Lamp, J. Illum. Engng. Jpn., 73-2, pp.4651(1989)(in Japanese).

(5) A.W. Serres: Reducing the Length of an Integrated Compact Fluorescent Lamp, J. Illum. Engng. Soc., 23-2, pp. 26-30(1994).

(6) Matsumoto and Yasuda: NETSUKAIRO KAISEKIWO MOTII-TA DENKYUGATA KEIKO Lamp-NO NETU-KAISEKI (Study on Heat Release of SelfBallasted Compact Fluorescent Lamp Using HeatTransfer Network Analysis), Proc. the 27th Tokyo Branch Meet. IEI Jpn., No.12 (2001)(in Japanese).

(7) Takahara, Ikeda and Yasuda: Development of Selfballasted compact fluorescent lamp with reflector globe, Proc. 2002 Annual Conf. of IEI Jpn., No.5(2002)(in Japanese).

(8) Toda, Yasuda and Takahara: RYUTAI KAISEKI Soft-wo MOCHIITA DENKYUGATA KEIKO LampNO NETSUKAISEKI (Heat Analysis of SelfBallasted Compact Fluorescent Lamp Using Software for Fluid Analysis), Proc. the 28th Tokyo Branch Meet. IEI Jpn., No.4(2002)(in Japanese).

(9) T. Yasuda, T. Tanaka, K. Nishio and M. Izumi: Technical Issues on the Electronic Compact Fluorescent Lamp Covered with a Diffusive Globe, J. Light \& Vis. Env., 23-2, pp.10-15(1999).

(10) Ishizuka: DENSHIKIKI-NO NETSUSEKKEI-TO NETSUKAIROMOUHOU-NO OUYOU (Thermal Design of Electronic Appliances and Application of 
Heat-Transfer Network Method), DENSHI GIJUTSU (Electronic Engng). 2002-No.11, pp.1215(2002)(in Japanese).

(11) Kunimine: Electronics-NO TAMENO NETSUSEKKEI KANZEN NYUUMON (Complete Introduction to Heat Design for Electronics), Nikkan Kogyo Shinbun-sha, p.36(1997)(in Japanese).

(12) Toshiba Lighting \& Technology Corp.: Lamp Gen- eral Catalogue(2003)(in Japanese).

(13) J.P. Holman (Author), K. Hirata (Translation Supervisor): DENNETSU KOUGAKU (Heat Transfer), Maruzen, p. 268 (1982)(in Japanese).

(14) Japan Electric Lamp Manufacturers Association: NIHON DENKYU KOUGYO-SHI DAI 4 TSUTHOBAN (History of Electric Lamp Manufacturing in Japan, Supplement No.4), p.55(2003)(in Japanese). 